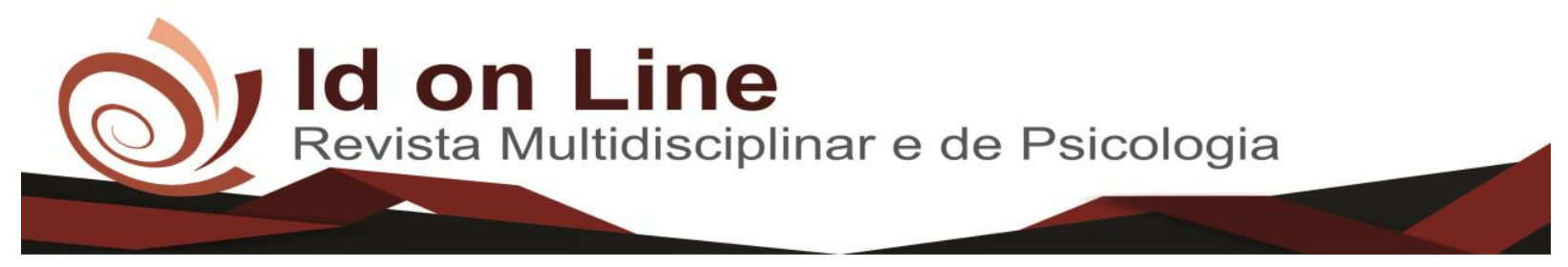

Artigo

\title{
Marketing Contábil: Um Estudo em Escritórios de Contabilidade do Município de Icó, Ceará-Brasil
}

\author{
Hernandes Adauto de Limal ; Antoniel dos Santos Gome Filho ${ }^{2}$
}

\begin{abstract}
Resumo: Com o marketing as empresas, inclusive os escritórios de contabilidade, podem apresentar um padrão de responsabilidade com a criação, divulgação e manutenção da marca, produto ou serviço. Desse modo o presente estudo tem como objetivo verificar como acontece uso do marketing pelos escritórios de contabilidade no município de Icó no Estado do Ceará. Metodologicamente a investigação possui uma abordagem qualitativa, e quanto aos objetivos a investigação é de nível exploratória e descritiva. Foi realizada uma pesquisa de campo junto a escritórios contábeis. Foram critérios de inclusão: (01) o escritório ter sede no município de Icó-CE, e, (02) o contador responsável possuir registro ativo no Conselho Regional de Contabilidade (CRC-CE). Frente aos critérios apresentados, foram incluídos na pesquisa 12 escritórios, e para a coleta de dados foi desenvolvido com base na literatura específica do tema marketing contábil um questionário estruturado contendo 5 questões especificas, as respostas foram analisadas com base na análise do conteúdo. Considera-se diante da pesquisa que: os contadores responsáveis pelos escritórios de contabilidade do município de Icó no Estado do Ceará apresentam um nível satisfatório de conhecimento sobre o marketing; os contadores participantes da pesquisa apontaram que era necessário e importante a introdução e/ou efetivação da disciplina de marketing na formação do profissional contábil durante a graduação; e, que os escritório de contabilidade do município de Icó-CE seguem estratégias de marketing pois, os mesmos buscam um relacionamento com seus clientes seja de modo presencial ou virtual.
\end{abstract}

Palavras-Chave: Marketing Contábil. Escritórios de Contabilidade. Icó-CE.

\section{Accounting Marketing: A Study in Accounting Offices of the Municipality of Icó, Ceará, Brazil}

\begin{abstract}
With marketing companies, including accounting offices, can present a standard of responsibility with the creation, disclosure and maintenance of the brand, product or service. Thus, the present study aims to verify how the use of marketing by the accounting offices in the municipality of Icó in the State of Ceará occurs. Methodologically the research has a qualitative approach, and as far as the objectives the research is of exploratory and descriptive level. A field survey was conducted with accounting offices. The inclusion criteria were: (01) the office is based in the municipality of Icó-CE, and, (02) the accounting officer has an active registration with the Regional Accounting Council (CRC-CE). In view of the criteria presented, 12 offices were included in the survey, and for the collection of data was developed based on the literature specific to the subject marketing accounting a structured questionnaire containing 5 specific questions, the answers were analyzed based on content analysis. It is considered before the research that: the accountants responsible for the accounting offices of the municipality of Icó in the State of Ceará present a satisfactory level of knowledge about marketing; the accountants who participated in the research pointed out that it was necessary and important to introduce and / or implement the marketing discipline in the training of the accounting professional during graduation; and that the accounting offices of the municipality of Icó-CE follow marketing strategies because they seek a relationship with their clients either in person or in virtual mode.
\end{abstract}

Keywords: Accounting Marketing. Accounting Offices. Icó-CE

\footnotetext{
${ }^{1}$ Concludente do curso de Ciências Contábeis da Faculdade Vale do Salgado (FVS). E-mail: hernandeslimma@ hotmail.com

2 Mestre em Educação pela Universidade Federal do Ceará (UFC). Professor da Faculdade Vale do Salgado (FVS). Coordenador do Laboratório Interdisciplinar em Estudos Organizacionais e do Trabalho (LIEOT-FVS). Pesquisador do Laboratório Interdisciplinar em Estudos da Violência no Centro Universitário Dr. Leão Sampaio (LIEV-UNILEÃO). E-mail: antonielsantos@fvs.edu.br
}

62 Id on Line Rev. Mult. Psic. V.13, N. 43, p. 62-75, 2019 - ISSN 1981-1179
Edição eletrônica em http://idonline.emnuvens.com.br/id 


\section{Introdução}

\footnotetext{
"Marketing é um conjunto de técnicas voltadas à maximização da percepção de felicidade das pessoas pela satisfação de necessidades e desejos, otimizando o retorno para organização." (AMBRÓSIO, 2007, p. XIII).
}

Com o marketing as empresas, inclusive os escritórios de contabilidade, podem apresentar um padrão de responsabilidade com a criação, divulgação e manutenção da marca, produto ou serviço. O marketing utiliza de várias técnicas e ferramentas como promoção, publicidades audiovisuais etc. Dessa forma a boa utilização do marketing pode trazer melhorias para a empresa e assim criar um diferencial no mercado.

O marketing está diretamente relacionado aos estudos de mercado, e busca compreender as relações entre clientes e organizações, e o desempenho organizacional. O marketing está presente na profissão contábil, e sendo bem trabalhado nos escritórios de contabilidade pode ser um meio eficaz para trazer novos clientes, alavancando as atividades, e gerando um maior retorno monetário em tempos de crise financeira que vivemos nos dias atuais.

O marketing contábil já foi tema de pesquisa em outros municípios do país. O estudo de Farias (2016) apresenta que a grande maioria dos escritórios de contabilidade da cidade de Campina Grande-PB utilizam o marketing contábil para permanecer concorrendo no mercado de trabalho, e, segundo Batista (2014) uma das técnicas de marketing mais utilizadas na cidade de Cacoal no Estado de Rondônia, é a apresentação pessoal e o relacionamento direto com o cliente.

Como pode ser visto nos estudos já publicados, o tema: Marketing Contábil constituise de uma problemática ampla, assim, diante das observações empíricas e da literatura específica, se faz uma inferência ao município de Icó no Estado do Ceará, que conta com diversos escritórios de contabilidade. Desse modo tem-se a seguinte pergunta problema: Como acontece uso do marketing pelos escritórios de contabilidade no município de Icó no Estado do Ceará?

Diante dessa problemática o objetivo do presente estudo tem por objetivo verificar como acontece uso do marketing pelos escritórios de contabilidade no município de Icó no Estado do Ceará. Especificamente foram objetivos da investigação: (01) identificar o conhecimento sobre os meios de divulgação dos contadores; e, (02) analisar como o marketing contribui para a valorização profissional do contador. 
O propósito de estudar sobre o marketing utilizado pelos contadores, surgiu das observações empíricas nos escritórios de contabilidade da cidade de Icó-CE. Tradicionalmente os empresários tendem a enxerga o escritório de contabilidade como local para "pagar imposto". Logo, uma visão distorcida das funções que os escritórios de contabilidade e das inúmeras funções que auxiliam na tomada de decisão do empresário.

O estudo se justifica diante da importância que a boa utilização do marketing contábil pode trazer para o empresário e contador, sempre observando o código de ética da classe contábil. A presente investigação encontra-se organizada nas seguintes seções: Marketing Contábil; Metodologia; Resultados e Discussões; Considerações Finais, seguido das referências utilizadas para o desenvolvimento teórico-metodológico da investigação.

\section{Marketing Contábil no Brasil}

Marketing é uma palavra proveniente da língua inglesa que de certo modo está intrínseca à cultura mundial. Em inglês, market significa mercado, e Marketing pode ser traduzido muitas vezes no sentindo de mercadologia, ou seja, o estudo das causas, objetivos e resultados que são gerados através das diferentes formas como nós lidamos com o mercado (MESQUITA, 2015).

Segundo Philip Kotler (1998, p. 37) o conceito de marketing “assume que a chave para atingir as metas organizacionais consiste em ser mais eficaz que os concorrentes para integrar as atividades de marketing, satisfazendo, assim, as necessidades e desejos dos mercadosalvos.". Ainda segundo o autor, o conceito de marketing apresenta-se em quatro pilares, a saber: (01) mercado-alvo; (02) necessidade dos consumidores; (03) marketing integrado; e, (04) rentabilidade. Sendo que o mercado-alvo, diz respeito ao nicho de mercado que a organização busca atingir; a necessidade dos consumidores, que busca conhecer plenamente os gostos, desejos e vontades do consumidor; o marketing integrado, que agrega o conjunto de todos os setores da organização nos planejamentos e estratégias de marketing; e, a rentabilidade, que está ligado no processo das organizações atingirem suas metas (KOTLER, 1998).

As empresas que possuem um Plano de Marketing bem elaborado, em especial os escritórios de contabilidade, estão à frente de seus concorrentes. Segundo Silva e Vieira (2012, p. 2) “o mercado em geral tem se tornado bastante criterioso em relação às suas preferências e o motivo que torna esses consumidores mais seletivos se relaciona diretamente com o seu nível de informação.”. Logo, as organizações devem em seu plano de marketing obter o maior número de informações sobre seus clientes, para que assim possam ofertar melhor seus serviços 
e produtos. Alexandre Luzzi Las Casas informa que as variáveis ambientais, ou seja, o ambiente mercadológico, deve ser analisado, pois muitas de suas variáveis são incontroláveis, mas, muitas das informações sobre o consumidor estão presentes no ambiente, assim, "a informação é uma ferramenta estratégica para muitas empresas. Pela constatação da necessidade de estar conectado no mercado, passou-se a desenvolver novas técnicas que auxiliam a captação de dados." (LAS CASAS, 2010, p.108).

Com a crescente concorrência no mercado de escritórios de contabilidade o marketing torna-se essencial para a criação de um diferencial competitivo na disputa de clientes. Os escritórios podem oferecer os mesmos serviços, mas com um plano de marketing bem elaborado e colocado em prática podem conseguir mais clientes e assim alavancando suas receitas.

A função do contador é fornecer aos clientes informações, que ajude na tomada de decisão, assim demostrando sua relevância nos processos de gestão das organizações. O contador desempenha suas funções com a ética e responsabilidade que lhe foi atribuída, desta forma foi elaborado o Código de Ética da profissão contábil em 1970, por meio da resolução do Conselho Federal de Contabilidade (CFC) n n 290/70, posteriormente alterado em 1996 pela resolução do CFC n 803/96 que tem como ênfase em seu primeiro artigo que o Código de Ética tem como objetivo fixar a forma pela qual o profissional deve se conduzir na sua carreira.

Todo profissional contábil deve observar o Código de Ética em seu desempenho profissional, assim não terá problemas ao exercer o que lhe é de ordem. Com a alta no mercado de escritórios de contabilidade, o contador, enquanto empreendedor deve buscar formas de se diferenciar no mercado, utilizando o marketing, e suas ferramentas. Deve-se apontar que o Código de Ética do Profissional Contador estabelece a seguintes norma de conduta profissional:

\footnotetext{
Art. $3^{\circ}$ No desempenho de suas funções, é vedado ao Profissional da Contabilidade: (Redação alterada pela Resolução CFC $n^{o} 1.307 / 10$, de 09/12/2010)

I - anunciar, em qualquer modalidade ou veículo de comunicação, conteúdo que resulte na diminuição do colega, da Organização Contábil ou da classe, em detrimento aos demais, sendo sempre admitida a indicação de títulos, especializações, serviços oferecidos, trabalhos realizados e relação de clientes;

(Redação alterada pela Resolução CFC n $n^{o}$ 1.307/10, de 09/12/2010) (CFC, 1996, p. $3)$.
}

Caso o profissional contábil venha a infringir o artigo citado, o mesmo pode sofrer sansões previstas, o que refletirá diretamente em sua imagem profissional, bem como na imagem da própria classe, desta forma o Código de Ética do Profissional Contador estabelece em seu Artigo 12: 
Art. 12 A transgressão de preceito deste Código constitui infração ética, sancionada, segundo a gravidade, com a aplicação de uma das seguintes penalidades:

I - advertência reservada;

II - censura reservada;

III - censura pública.

(CFC, 1996, p. 11).

Desse modo, tendo em vista tais prerrogativas, o marketing deve ser bem planejado, e acompanhado diretamente pelos gestores e/ou contadores dos escritórios de contabilidade. O marketing contábil segundo Hernandes (2011, s/p) é um "conjunto de estratégias, planejamento e atividades visando à promoção, venda e o atendimento de necessidades e desejos de consumidores dos serviços prestados por contabilista.". O autor destaca que durante a formação do profissional contador não há a obrigatoriedade de cursar uma disciplina de marketing, o que pode dificultar sua entrada no mercado. Fahl e Manhani (2009) também destacam a importância da disciplina de marketing contábil na formação profissional. Pois, como aponta Martins (2017, p. 9), "além de possuir competências tradicionalmente relacionadas à contabilidade (societária, tributária e auditoria), precisa estar apto a participar do processo de gestão das empresas, comunicando e interagindo com as demais áreas organizacionais, de forma que possa contribuir com a resolução dos problemas.”.

Outro pondo de destaque envolve o marketing pessoal, ou seja, as ações e planejamentos de divulgação que estão ligadas a imagem do indivíduo, nesse caso, o profissional contábil. Pereira e Leite Filho (2002) apontam que a comunicação entre profissional contador e cliente é fundamental para que os serviços sejam oferecidos de modo claro, atendendo assim as expectativas dos mesmos. Os autores também apontam que o Marketing Pessoal está correlacionado ao profissional como um produto, desse modo, o mesmo deve ter cuidados com sua aparência pessoal, pois, "o profissional é um produto! Mas, se quiser fazer sucesso no mercado de trabalho, precisa acreditar nisso de verdade, e agir! Sem se enxergar como um produto, o profissional contábil, dificilmente conseguirá conquistar seus clientes" (Pereira; Leite Filho, 2002, p. 28).

No Brasil, Dedonatto et al. (2004) em estudo sobre marketing contábil realizado com 37 escritórios de contabilidade do município de Chapecó, Santa Catarina, apontou que 40,54\% tinham um bom entendimento sobre marketing; 37,84\% conhecimento razoàvel; $16,22 \%$ um ótimo conhecimento, e, 5,41\% não possuem conhecimento. Os participantes informaram que no cotidiano as práticas de marketing acontece somente às vezes, 48,65\%; 29,73\% não praticam e 21,62\% praticam diariamente. De acordo com Dedonatto et al. (2004) com base na pesquisa 
observa-se uma não utilização do marketing por parte dos contadores, dificultando assim um processo de diferenciação.

Peleias et al. (2007) apresentam resultados de uma pesquisa realizada no último trimestre de 2004 e primeiro trimestre de 2005, onde foram pesquisados 259 escritórios de contabilidade do Estado de São Paulo que utilizam os instrumentos de marketing. A pesquisa apontou (fator: orientação e satisfação do cliente) que os escritórios buscaram manter equipes estáveis, para manter um bom atendimento aos clientes, uma vez que, é necessário a confiança da clientela, aumentando a propaganda "boca-a-boca", destaca-se que os participantes não mencionaram ferramentas de marketing para estreitar os vínculos com os clientes.

O estudo de Grazieli Porto Nunes (2013) investigou a retenção dos clientes em escritórios contábeis no município de Caxias do Sul-RS, dos 9 escritórios investigados, constatou-se que o fator qualidade no trabalho é fundamental para retenção dos clientes. Segundo a pesquisa os motivos para permanência dos clientes estão correlacionados ao comportamento dos escritórios e como os clientes são tratados nestes, destaca-se que os clientes estão preocupados em "contratar um prestador de serviço com prestígio e respeito no mercado" (NUNES, 2013, p. 33), logo, o marketing pessoal é um fator fundamental na gestão dos escritórios contábeis.

Jordânio Pinheiro Batista (2014) realizou uma pesquisa sobre marketing contábil no município de Cacoal no Estado de Rondônia onde foi constatado que as práticas de marketing são fundamentais para as atividades dos escritórios (62,5\%). Destaca-se que 50\% concordam muito e $31,25 \%$ concordam totalmente, que a disciplina de marketing contábil deve estar nas matrizes curriculares dos cursos de Ciências Contábeis.

No nordeste brasileiro, a investigação de Wadamir Lemos de Farias (2016), intitulado: $O$ uso de ferramentas de marketing como estratégia competitiva para escritórios de contabilidade, apontou quais eram as ferramentas de marketing utilizadas pelos escritórios contábeis do município de Campina Grande no Estado da Paraíba. Com base nos questionários aplicados em 23 escritórios, teve-se como resultado em relação ao conhecimento: 52,2\% bom conhecimento, $26,1 \%$ conhecimento razoável, 17,4\% ótimo conhecimento e 4,3\% não possui conhecimento. No que tange a publicidade, destaca-se que 91,3\% dos escritórios afirmam que investem em publicidade, sendo que a confecção de cartões $(95,3 \%)$ e a confecção de agendas e brindes $(76,2 \%)$ constituem-se como foco da publicidade. Destaca-se que 56,5\% possuem páginas nas redes sociais. No que tange os investimentos em marketing anualmente a pesquisa de Farias apresenta os seguintes resultados: 8,4\% não investe; 17,4 investe até 500 reais; 34,8\% 
investe até 1000 reais; $17,4 \%$ até 3000 reais; $17,4 \%$ até 5000 reais, e, 4,3\% entre 5000 e 10.000 mil reais.

\section{Metodologia}

A presente pesquisa foi desenvolvida no município de Icó no Estado do Ceará, que segundo o Instituto Brasileiro de Geografia e Estatística (IBGE) tem uma população estimada em 67.486 habitantes. A investigação possui uma abordagem qualitativa (FLICK, 2009; 2009a), quanto aos objetivos a investigação é de nível exploratória e descritiva, onde segundo Antonio Carlos Gil (2009, p.27-28) o primeiro nível tem como finalidade "proporcionar uma visão geral, de tipo aproximativo, acerca de determinado fato", já o segundo busca "a descrição das características de determinada população ou fenômeno [...]".

Desse modo, o primeiro passo da pesquisa foi marcado por uma pesquisa bibliográfica, que de acordo com Marconi e Lakatos (2017, p. 33) "é feita com base em textos, como livros, artigos científicos, ensaios críticos, dicionários, jornais [...]”. Aponta-se que buscou-se um foco nos artigos científicos publicados na área de marketing contábil. A pesquisa bibliográfica foi apresentada na seção: Marketing contábil no Brasil. O segundo passo da pesquisa, consistiu em uma pesquisa de campo, junto a escritórios contábeis. Foram critérios de inclusão: (01) o escritório ter sede no município de Icó-CE, e, (02) o contador responsável possuir registro ativo no Conselho Regional de Contabilidade (CRC-CE).

Frente aos critérios apresentados, foram incluídos na pesquisa 12 escritórios, tendo em vista os aspectos éticos, o nome dos contadores e escritórios não são apresentados nos resultados da investigação.

Para a coleta de dados junto aos 12 escritórios foi desenvolvido com base na literatura especifica do tema marketing contábil um questionário estruturado contendo 5 questões especificas, a saber: (01) Qual seu entendimento/conhecimento sobre marketing?; (02) Qual sua opinião sobre o marketing ser introduzido na grade curricular do bacharel em ciências contábeis?; (03) Você utiliza alguma estratégia/ferramenta de marketing no escritório?; (04) O escritório possui um plano de marketing? Se sim, como vem sendo utilizado? e, (05) Como você ver os benefícios do marketing contábil para a empresa?

A aplicação do questionário aconteceu no mês de Outubro de 2018, sendo que as respostas foram analisadas com base na análise do conteúdo, que de acordo com Gil (2009) envolve uma pré-análise, que envolve a organização dos dados coletados em campo, seguido 
da exploração do material, finalizado com o tratamento, inferência e interpretação. Portanto, os resultados e discussões do presentes estudo seguem essas etapas.

\section{Resultados e Discussões}

Como visto no decorrer do estudo, o marketing contábil tem sido alvo de diversos estudos nos mais diversos pontos do Brasil (DEDONATTO et al., 2004; PELEIAS et al., 2007; NUNES, 2013; BATISTA, 2014; FARIAS, 2016). Destaca-se que os estudos buscaram conhecer o nível de entendimento/conhecimento dos profissionais contábeis sobre marketing, desse modo foi indagado aos profissionais contábeis de Icó-CE ${ }^{3}$ : (01) Qual seu entendimento/conhecimento sobre marketing? As respostas podem ser visualizadas na tabela 01:

Tabela 01: Nível de entendimento/conhecimento sobre marketing

\begin{tabular}{c|c}
\hline Contador 1 & $\begin{array}{c}\text { São ferramentas que a empresa utiliza estrategicamente para suprir o desejo dos } \\
\text { consumidores e obter êxito na empresa. }\end{array}$ \\
\hline Contador 2 & Investimento em publicidade. \\
\hline Contador 3 & Marketing e a forma de como você "se vende" (habilidades e competências). \\
\hline Contador 4 & Bom. \\
\hline Contador 5 & Marketing e uma maneira de ter o diferencial no mercado. \\
\hline Contador 6 & Estratégias empresarial, e campanhas comercias. \\
\hline Contador 7 & Marketing é o processo de planejar e executa uma ideia que vise ter uma valor. \\
\hline Contador 8 & É o conjunto de estratégias e ações relativas a desenvolvimento, distribuição e promoção \\
Contador produtos ou serviço.
\end{tabular}

Fonte: Dados da pesquisa (2018)

Como pode ser analisado, os respondentes apresentam um nível satisfatório no que tange o entendimento sobre o marketing, mas, pode-se perceber que alguns profissionais contábeis fazem uma correlação com a publicidade, ou seja, no modo como a empresa será divulgada junto a seus clientes. Diante das respostas também percebe-se uma orientação para o cliente, como pode ser visto na resposta do Contador 01 e Contador 11; essa orientação vai de encontro aos estudos de Ambrósio (2007), quando o autor destaca que o marketing busca a satisfação

\footnotetext{
${ }^{3}$ Breve perfil dos pesquisados: Sexo: Masculino (41,6\%) e Feminino (58,4\%). Tempo de atividade no escritório: 0 a 5 anos (16,7\%); 6 a 10 anos (33,3\%); e, 11 a 15 anos (50\%). Tomou conhecimento sobre o Código de Ética do Profissional Contador: Durante a graduação $(58,4 \%)$; Através dos meios de comunicação $(8,4 \%)$; e, Outros $(33,2 \%)$.
} 
dos desejos dos consumidores. Os estudos de Dedonatto et al. (2004) e Farias (2016) apresentaram níveis satisfatórios de conhecimento sobre o marketing contábil.

Estudar sistematicamente o marketing é necessário para ampliar os conhecimentos que envolvem o planejamento e as aplicações do marketing nos escritórios contábeis. Como visto na pesquisa bibliográfica, autores como Batista (2014), Fahl e Manhani (2009) e Martins (2017) defendem e apontam que é necessário a introdução da disciplina de marketing na formação contábil. Desse modo, foi indagado aos pesquisados: (02) Qual sua opinião sobre o marketing ser introduzido na grade curricular do bacharel em ciências contábeis?

Tabela 02: Introdução da disciplina de marketing na formação contábil

\begin{tabular}{c|c}
\hline Contador 1 & Bem interessante, já que uma ferramenta para agradar o cliente e desenvolver a empresa. \\
\hline Contador 2 & É importante. O contador precisa saber divulgar seus serviços. \\
\hline Contador 3 & $\begin{array}{r}\text { Muitos utilizam essa ferramenta de forma incoerente, então seria necessário a forma } \\
\text { correta, sendo estudada em sala. }\end{array}$ \\
\hline Contador 4 & Desnecessário. \\
\hline Contador 5 & Muito importante, pois abriria uma visão maior do sucesso. \\
\hline Contador 6 & $\begin{array}{c}\text { Marketing é um instrumento importantíssimo para o profissional, desde o marketing } \\
\text { pessoal ao da empresa, desta forma e de suma importância para o profissional. }\end{array}$ \\
\hline Contador 7 & $\begin{array}{c}\text { Muito importante. Pois o mercado de trabalho exige muito e para quem está introduzindo } \\
\text { nesse meio, recém formado teria mais chances. }\end{array}$ \\
\hline Contador 8 & O marketing, vem auxiliar a organização e suas tomadas de decisões. \\
\hline Contador 9 & $\begin{array}{r}\text { Um passo importante para o aprendizado do curso de ciências contábeis, objetivando um } \\
\text { desempenho empreendedor na vida e nos negócios. }\end{array}$ \\
\hline Contador 10 & Acho desnecessário, tendo em vista que o curso e voltado quase exclusivamente para \\
& teoria. \\
\hline Contador 11 & Ótima ideia, pois daria um norte para quem e recém formado. \\
\hline Contador 12 & São boas, possível identificar seus reais conhecimentos de mercado e aprendizado. \\
\hline
\end{tabular}

Hernandes (2011) e Martins (2017) destacam que no atual cenário mercadológico, onde os processos de globalização e integração das informações e comunicação se fazem presentes, o profissional da contabilidade deve desenvolver novas habilidades e competências, para além dos aspectos teóricos. Logo, a formação contábil está cada vez mais ampliada, diferentemente da percepção do Contador 4 e Contador 10, como diz Martins:

O perfil desse profissional, além de possuir competências tradicionalmente relacionadas à contabilidade (societária, tributária e auditoria), precisa estar apto a participar do processo de gestão das empresas, comunicando e interagindo com as demais áreas organizacionais, de forma que possa contribuir com a resolução dos problemas (MARTINS, 2017, p. 09).

Logo, diante desse panorama atual, e analisando as respostas dos Contadores (exceto 4 e 10) observa-se a importância da introdução e/ou efetivação da disciplina de marketing na formação do profissional contábil, pois como ressaltado pelos pesquisados, tal conhecimento 
auxiliará o profissional em início de carreira em sua inserção no mercado, ou mesmo subsidiará os profissionais já inseridos nos processos planejamento, pesquisa de mercado, na promoção e divulgação dos serviços, dentre outras aplicações do marketing nas organizações.

Indagados sobre a utilização de ferramentas de marketing nos escritórios, os participantes responderam que:

Tabela 03: Uso das estratégias/ferramentas de marketing nos escritórios

\begin{tabular}{l|c}
\hline Contador 1 & Divulgação via internet. \\
\hline Contador 2 & Não. \\
\hline Contador 3 & Sim, através de programa de rádio e cartão de visita. \\
\hline Contador 4 & Não. \\
\hline Contador 5 & Não. \\
\hline Contador 6 & Sim, marketing pelas rede sociais e rede de contatos. \\
\hline Contador 7 & Não. \\
\hline Contador 8 & Sim. \\
\hline Contador 9 & Sim, cartão de visita e o famoso "boca-a-boca". O preço também não deixa de ser um \\
& instrumento. \\
\hline Contador 10 & Sim, marketing digital e anuncio em catálogos. \\
\hline Contador 11 & Sim, cartões de visita e internet. \\
\hline Contador 12 & Sim, através de Fardamentos, assessorias, relações públicas, propaganda e divulgação. \\
\hline
\end{tabular}

Fonte: Dados da pesquisa (2018)

Apesar dos Contadores 2, 4, 5 e 7 informarem que não fazem uso de nenhuma estratégia/ferramenta de marketing, destaca-se que os demais escritórios buscam manter um diferencial no mercado, e uma aproximação com os clientes, seja através das relações pessoais com seus clientes, sejam estas presenciais ou virtuais, como apontam os Contadores 1, 6, 10 e 11, que desenvolvem ações de marketing digital. Já os Contadores 3, 9 e 12 utilizam estratégias/ferramentas mais tradicionais, tais como, a utilização e distribuição de cartões de visita, o anuncio em rádios e a propaganda boca-a-boca. Tais estratégias/ferramentas também foram elencadas no estudo Farias (2016) sendo que a confecção de cartões de visita tem um grande destaque no processo de divulgação dos escritórios de contabilidade, tal proposição também pode ser vista nos escritórios do município de Icó-CE.

O planejamento de marketing é fundamental para que as organizações consigam atingir seus objetivos junto ao mercado, como aponta Las Casas:

Planejar consiste em tomar antecipadamente um conjunto de decisões. Os administradores estudam o ambiente e, a partir de uma análise de suas possíveis influencias, estabelecem objetivos e estratégias para determinado período. Estas iniciativas ajudam a orientar os vários passos que uma organização deve tomar. Portanto, com o planejamento é possível desenvolver atividades coerentes (LAS CASAS, 2010, p. 81). 
Tendo em vista a importância de produzir um planejamento de marketing para as organizações, inclusive para os escritórios de contabilidade, nota-se que ainda não há um planejamento nos escritórios investigados, pois os Contadores 1, 2, 3, 4, 5, 7 e 11, informaram que não há esse tipo de planejamento. Já os Contadores 6, 8 e 9 apontaram que possuem um planejamento, informando respectivamente: "Sim, está sendo bem utilizado, alcançamos bons números nas redes gerenciadas."; "Sim, procuramos sempre a melhor estratégia para o escritório"; "Sim. O marketing e uma ferramenta de gestão que deve ser utilizada sempre, sua utilização auxilia os empreendedores a se adaptar as constantes mudança do mercado, está sendo bem utilizado.". O Contador 10 informou que no início das atividades do escritório havia feito, porém no momento não conta mais com o plano.

Por fim, foi indagado aos pesquisados quais eram os benefícios que o marketing contábil traria para a empresa e/ou escritório. As respostas podem ser vistas na tabela 04:

Tabela 04: Benefício do marketing para escritórios

\begin{tabular}{|c|c|}
\hline Contador 1 & $\begin{array}{c}\text { Divulgação do trabalho, qualificação do serviço, obtenção de lucros, conhecer o público- } \\
\text { alvo. }\end{array}$ \\
\hline Contador 2 & Espera-se que por meio da propaganda, se obtenha mais clientes. \\
\hline Contador 3 & $\begin{array}{l}\text { Quando o marketing e utilizado como ferramenta de forma adequada, seu trabalho e bem } \\
\text { visto e assim atraindo mais clientes, como também parcerias. }\end{array}$ \\
\hline Contador 4 & Não pode. É proibido. \\
\hline Contador 5 & Sempre que bem utilizado pode gerar muitos benefícios, exemplo: o financeiro. \\
\hline Contador 6 & $\begin{array}{l}\text { E perceptível o conhecimento que os clientes obtiveram após as nossas divulgação, } \\
\text { aumentou a confiança dos cliente, tanto o quanto, os clientes que não nos conheciam. }\end{array}$ \\
\hline Contador 7 & Não tenho. \\
\hline Contador 8 & O marketing vem ajudar a consolidar o nome do seu escritório da melhor forma possível. \\
\hline Contador 9 & $\begin{array}{c}\text { Confiança, relacionamento, cliente. Tudo isso são vantagens que a empresa adquirir com } \\
\text { marketing certo. }\end{array}$ \\
\hline Contador 10 & Divulgar a marca, captar novos clientes, engajar antigos e crescer. \\
\hline Contador 11 & Pode ser o diferencial. \\
\hline Contador 12 & Vejo com bons olhos, acredito que o marketing e hoje a principal ferramenta de trabalho. \\
\hline
\end{tabular}

Fonte: Dados da pesquisa (2018)

Nota-se entre os respondentes, com exceção dos Contadores 4 e 7, que o marketing na visão dos pesquisados apresenta benefícios para os escritórios. Destaca-se que o fator propaganda/divulgação é bastante ressaltado, uma vez que é através desta que o escritório, bem como o profissional contábil fica (re)conhecido no que tange a prestação e oferecimento de serviços contábeis no mercado local onde está inserido. 


\section{Considerações Finais}

O objetivo do presente estudo foi verificar como acontece uso do marketing pelos escritórios de contabilidade no município de Icó no Estado do Ceará. Para tal foi realizado uma pesquisa de campo no referido município junto a 12 escritórios de contabilidade, sendo os respondentes dos questionários os respectivos profissionais de contabilidade. Destaca-se que investigações científicas com o mesmo escopo já foram realizadas noutras localidades do Brasil, demonstrando assim a importância e interesse de pesquisadores no tema marketing contábil.

Diante dos subsídios bibliográficos e da pesquisa de campo pode-se apresentar as seguintes considerações:

1) Os contadores responsáveis pelos escritórios de contabilidade do município de Icó no Estado do Ceará apresentam um nível satisfatório de conhecimento sobre o marketing, sendo que, sua orientação está em geral correlacionada a promoção e divulgação dos produtos e serviços, e, nos processos de satisfação dos clientes.

2) Como já apontado em outras pesquisas sobre marketing contábil no Brasil, a exemplo: Hernandes (2011), Batista (2014) e Martins (2017), os contadores participantes da pesquisa apontaram que era necessário e importante a introdução e/ou efetivação da disciplina de marketing na formação do profissional contábil durante a graduação.

3) Em relação ao planejamento de marketing observou-se que alguns dos contadores pesquisados não realizam planejamento de marketing. Por outro lado, os contadores que utilizam, se apontaram que através do planejamento já percebem um retorno para o escritório.

4) Pode-se considerar que os escritórios de contabilidade do município de Icó-CE seguem estratégias de marketing também visualizadas noutros estudos (FARIAS, 2016), pois, os mesmos buscam um relacionamento com seus clientes seja de modo presencial ou virtual. Desse modo, os profissionais contadores percebem diretamente os benefícios do marketing contábil no fortalecimento de vínculo com os clientes e no crescimento e consolidação do escritório no mercado local. 
Portanto, pode-se considerar que a investigação agrega-se a tantas outras, que buscaram conhecer/verificar, em níveis locais como acontece o Marketing Contábil. Como visto na literatura, a Profissão Contábil tem se modificado ao longo dos anos, principalmente por conta dos processos de globalização, logo, novos conhecimentos, habilidades e competências tem sido exigidas desse profissional, o que influencia diretamente no processo formativo, com a inclusão de novas disciplinas nas matrizes curriculares dos cursos de bacharelado em ciências contábeis, no caso em estudo, o Marketing Contábil.

\section{Referências}

BATISTA. J. P. Marketing contábil: um estudo realizado com os gestores dos escritórios de contabilidade da cidade de Cacoal/RO. 2014. Trabalho de Conclusão de Curso (Monografia de Ciências Contábeis) - Universidade Federal de Rondônia, Cacoal, 2014.

BRASÍLIA. Conselho Federal de Contabilidade Lei $\mathbf{n}^{\mathbf{0}}$. 12.249/10. Altera o Decreto-Lei $\mathbf{n}^{\circ}$. 9.295/46, que se dispõe sobre o código de Ética Profissional que se aplica aos Contadores e Técnicos em Contabilidade. Disponível em: <http://www1.cfc.org.br/sisweb/SRE/docs/RES_803.pdf>. Acesso em: 20 Out. 2017.

Conselho Federal de Contabilidade. Código de Ética Profissional do Contador RESOLUÇÃO CFC No 803/96. 1996. Disponível em: <http://www.crcce.org.br/legislacao/codigo-de-etica/>. Acesso em: 10 Out. 2018.

DEDONATTO, O. et al. Marketing contábil: um instrumento de comunicação na estratégia competitiva profissional. Revista Catarinense da Ciência Contábil, v. 3, n. 9, 2004.

FAHL, A. C.; MANHANI, L. P. S. As perspectivas do profissional contábil e o ensino da contabilidade. Revista de Ciências Gerenciais. v.13, n. 18, 2009.

FARIAS, W L. O uso de ferramentas de marketing como estratégia competitiva para escritórios de contabilidade. 2016. Trabalho de Conclusão de Curso (Monografia de Ciências Contábeis) - Universidade Estadual da Paraíba, Campina Grande, 2016.

FLICK, U. Desenho da pesquisa qualitativa. Porto Alegre: Artmed, 2009a.

FLICK, U. Introdução à pesquisa qualitativa. 3. ed. Porto Alegre: Artmed, 2009.

GIL, A. C. Métodos e técnicas de pesquisa social. 6. ed. São Paulo: Atlas, 2009.

HERNANDES. Anderson. Conceitos de marketing aplicado ao mercado contábil. 2011, Disponível em: <http:// www.andersonhernandes.com.br/2011/05/16/ conceitos-demarketing-aplicado-ao-mercado-contabil/>. 
HERNANDES. Anderson. O marketing contábil e os profissionais de contabilidade. 2009, Disponível em: <http://www.andersonhernandes.com.br/2009/08/31/o-marketing-contabil-eos-profissionais-de-contabilidade/ $>$.

IBGE. Instituto Brasileiro de Geografia e Estatística. Censo Populacional 2010. 2010. Disponível em: <https://cidades.ibge.gov.br/brasil/ce/ico/panorama>.

KOTLER. Philip. Administração de marketing: análise, planejamento implementação e controle. 5. Ed. São Paulo: Atlas, 1998.

LAS CASAS, A. L. Administração de marketing: conceitos, planejamento e aplicações a realidade. São Paulo: Atlas, 2010.

MARCONI, M. A.; LAKATOS, E. M. Fundamentos de metodologia científica. 8.ed. São Paulo: Atlas, 2017.

MARTINS, A. F. C. As Perspectivas Profissionais dos Alunos do Curso de Ciências Contábeis da Universidade Federal de Goiás. 2017. Trabalho de Conclusão de Curso (Monografia de Ciências Contábeis) - Universidade Federal de Goiás, Goiânia, 2017.

MESQUITA. Renato. O que é marketing. 2015. Disponível em $<$ https://marketingdeconteudo.com/o-que-e-marketing/>.

NUNES, G. P. Um Estudo Sobre a Retenção de Clientes nos Escritórios Contábeis de Caxias do Sul - RS. Trabalho de Conclusão de Curso (Monografia de Ciências Contábeis) Universidade de Caxias do Sul, Caxias do Sul, 2013.

Peleias, I. R. et al. Marketing Contábil: pesquisa com escritórios de contabilidade no Estado de São Paulo. UnB Contábil, v. 10, n. 71, 2007.

Pereira, E, S.; Leite Filho, G. A. A influência do marketing no perfil do profissional contábil. Pensar Contábil, Fev-Abr, 2002.

SEBRAE. Serviço Brasileiro de Apoio às Micro e Pequenas Empresas. Como Elaborar um Plano de Marketing. 2017.2 Disponível em: http://www.sebrae.com.br/sites/PortalSebrae/bis/como-elaborar-um-plano-de-marketing>.

SILVA, R. B.; VIEIRA, L. B. A importância do planejamento estratégico de marketing na formulação do plano de negócios. Revista da FAC, v.6, 2012.

Como citar este artigo (Formato ABNT):

LIMA, Hernandes Adauto de; GOMES FILHO, Antoniel dos Santos. Marketing Contábil: Um Estudo em Escritórios de Contabilidade do Município de Icó, Ceará-Brasil. Id on Line Rev.Mult. Psic., 2019, vol.13, n.43, p. 62-75. ISSN: 1981-1179. 